\title{
Congenital cystic adenomatoid malformation presenting as in-flight systemic air embolisation
}

\author{
E. Belcher*, M.H. Lawson", A.G. Nicholson*, A. Davison\# and P. Goldstraw*
}

\begin{abstract}
Congenital cystic adenomatoid malformations (CCAMs) are rarely diagnosed in adulthood. The present case study reports a case of a CCAM presenting as a cerebral air embolus during an international flight.
\end{abstract}

In the present case, supportive therapy resulted in a full recovery. The patient later underwent elective excision of the pulmonary malformation.

Since the overall mortality of in-flight cerebral air embolisation is high, patients with such asymptomatic cysts should be considered for elective surgery.

\section{KEYWORDS: Congenital lung disease, stroke, thoracic surgery}

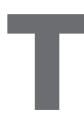

he term congenital cystic adenomatoid malformation (CCAM) of the lung encompasses a spectrum of conditions from disordered airway development (types 0, 1 and 2) to abnormalities in the development of alveolar parenchyma (type 4; table 1) [1]. Symptoms of the latter type commonly include respiratory failure or infection. The present case study describes a type-4 CCAM presenting as a cerebral air embolus during an international flight.

\section{CASE REPORT}

A 17-yr-old male nonsmoker collapsed suddenly 15 min after take-off during a flight from London, UK, to Salzburg, Austria. He had flown uneventfully on four previous occasions. He initially complained of generalised "pins and needles" followed by loss of consciousness and urinary incontinence without evidence of seizure. He regained consciousness shortly prior to landing. On admission to hospital, he had a left hemiparesis and bulbar palsy. Computed tomography (CT) and magnetic resonance imaging of the brain showed no abnormalities. An EEG was performed and found to be normal. Laboratory investigations were normal, with the exception of a mildly raised troponin $\mathrm{T}\left(0.07 \mathrm{ng} \cdot \mathrm{mL}^{-1}\right)$. All neurological signs and symptoms resolved within $72 \mathrm{~h}$ and hyperbaric oxygen therapy was not instituted. A chest radiograph (fig. 1) showed a large thin-walled cyst in the left upper lobe. CT of the chest (fig. 2) revealed a 9-cm thin-walled cystic airspace in the left upper lobe with peripherally displaced vessels. A further smaller cystic lesion was noted in the posterobasal segment of the left lower lobe. Transthoracic echocardiography was normal. Aspirin therapy was commenced and he returned to the UK by ground transportation 10 days after presentation. At his local hospital he underwent a normal transoesophageal echocardiogram effectively ruling out paradoxical embolisation via a patent foramen ovale. A ventilation scan showed absence of ventilation in the left upper zone lesion. Spirometry recorded a forced expiratory volume in one second of $4.35 \mathrm{~L}$ (98\% predicted) and a forced vital capacity of $4.82 \mathrm{~L}$ (92\% pred), with a residual volume of $1.89 \mathrm{~L}$ (114\% pred). He was referred for surgical treatment.

The patient remained well and underwent elective left thoracotomy, atypical excision of the left apical segment of the upper lobe and wedge resection of the lower lobe cyst. Histological examination of both lesions showed features characteristic of a type-4 CCAM, with disordered cystic dilated airspaces lined by type2 pneumocytes and the intervening thin septa comprising cytologically bland mesenchyme (fig. 3). No cellular areas to suggest blastomatous differentiation were seen. The post-operative course was uneventful and the patient was discharged 11 days after the operation.
AFFILIATIONS

*Dept of Thoracic Surgery and Histopathology, Royal Brompton Hospital, London, and

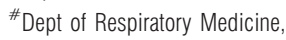
Southend University Hospital,

Southend, Essex, UK.

CORRESPONDENCE

P. Goldstraw

Dept of Thoracic Surgery

Royal Brompton Hospital

Sydney Street

London

SW3 6NP UK

Fax: 442073518560

E-mail: p.goldstraw@rbht.nhs.uk

Received:

November 262006

Accepted after revision:

May 162007

STATEMENT OF INTEREST

None declared. 


\begin{tabular}{lcccc}
\hline TABLE 1 & $\begin{array}{c}\text { Extended classification of congenital cystic adenomatoid malformations } \\
\text { Type }\end{array}$ & $\begin{array}{c}\text { Characteristic components of } \\
\text { lesion }\end{array}$ & $\begin{array}{c}\text { Proportional } \\
\text { incidence } \%\end{array}$ & Other features \\
\hline $\mathbf{0}$ & Tracheobronchial & $1-3$ & Solid & Neonates, poor prognosis \\
$\mathbf{1}$ & Bronchial/bronchiolar & $60-70$ & Large cysts $(\leqslant 10 \mathrm{~cm})$ & Delayed presentation \\
$\mathbf{2}$ & Bronchiolar & $10-15$ & Multiple small cysts $(\leqslant 2 \mathrm{~cm})$ & Neonates, poor prognosis \\
$\mathbf{3}$ & Bronchiolar/alveolar & 5 & Solid & Neonates, poor prognosis \\
$\mathbf{4}$ & Distal acinar & 15 & Large cysts $(\leqslant 10 \mathrm{~cm})$ & Neonates and infants, good prognosis \\
\hline
\end{tabular}

Adapted from [1, 2] with permission.

\section{DISCUSSION}

The differential diagnosis in the present case includes ischaemic, embolic or haemorrhagic cerebrovascular events or epipleptic seizure; however, the probable explanation for the presentation in this case is cerebral air embolisation from the left upper lobe cyst. Changes in atmospheric pressure may cause previously asymptomatic pulmonary cysts to rupture causing pneumothorax, haemothorax or air embolism. Gaseous embolism as a consequence of underwater diving is well recognised, but there are only three previous reports of air embolism during air travel, two of which were fatal [3-5]. This is the first reported case of air embolism as a result of a CCAM. All previous cases were associated with bronchogenic cysts. NeIDHART and SUTER [3] describe the pathophysiology of air embolism during air travel. At cruising altitudes of 9,144 m (30,000 feet), passenger aircrafts are pressurised to maintain a cabin pressure equivalent to $2,438.4 \mathrm{~m}$ (8,000 feet). During ascent, this results in a pressure drop from $760 \mathrm{mmHg}$ (at sea level) to $564 \mathrm{mmHg}$. The pressure changes described are reached within $20 \mathrm{~min}$ of take-off. In the present case, onset of symptoms occurred $15 \mathrm{~min}$ following take-off and previous reports of pulmonary cyst rupture during air travel describe onset of symptoms 10-20 min after commencement of the flight [3-5].

Fulfilment of Boyle's law (the inverse relationship of gas volume and pressure) would result in expansion of the cyst volume by one-quarter, assuming complete compliance. Lack of compliance increases the intracystic pressure with attendant risk of rupture. Rupture of the cyst wall may result in entrainment of air into adjacent pulmonary vessels whose walls have also been damaged during rupture of the cyst. The exact level of entry of air into the circulation is unknown. While this may occur at the alveolar capillary membrane, it may also result from rupture of the cyst into a larger traversing vessel associated with the cyst wall. It is likely that embolisation of air into the systemic circulation in the present patient resulted in cerebral ischaemia and probable myocardial ischaemia ensued, resulting in the neurological symptoms and signs, together with a transiently raised troponin level.

The present case and the previously reported cases share several characteristic features. All patients collapsed during decompression of the passenger cabin, all suffered primary brain injury and three, including the present case, had evidence of cardiac involvement. Although end-organ sites of air embolism include the kidneys, lungs, gastrointestinal tract and limbs, the propensity for the cerebral and coronary vessels may be due to the sitting position assumed during take-off or may simply reflect lack of functional reserve in the brain and the sensitivity of cardiac troponin as a marker for damage. While it is generally accepted that $>50 \mathrm{~mL}$ of air may be associated with hypotension and dysrhythmias, and $>300 \mathrm{~mL}$ of air may be fatal, there have been reports of air embolism with $<2 \mathrm{~mL}$ of entrained air. All cases had large cysts of $\geqslant 500 \mathrm{~mL}$, which were not in communication with the bronchial tree. Large cysts may be more likely to lead to air embolisation, as they contain a greater volume of air. However, the most important factor is probably cyst wall tension at sea level. Other possible influential factors are the mechanical properties of the cyst wall, including elasticity and the associated vascular anatomy. The rupture of the cyst, while causing air embolism, is not necessarily associated with pneumothorax or pneumomediastinum. In the

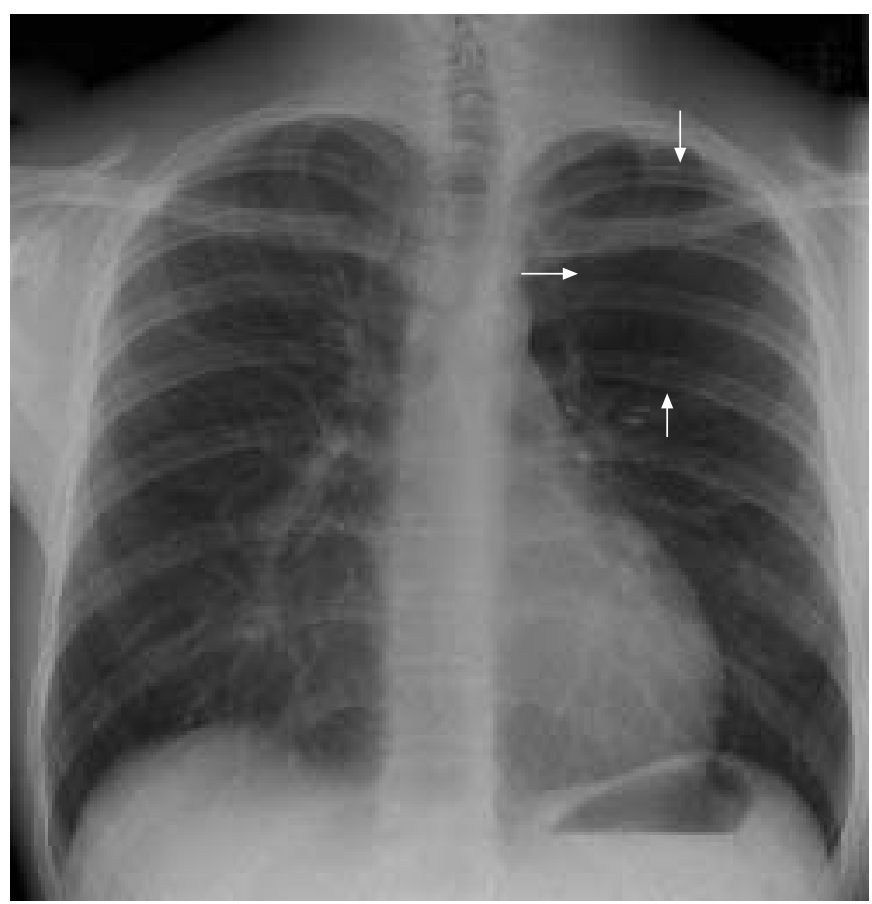

FIGURE 1. Chest radiograph demonstrating large thin-walled cyst in the left upper lobe (arrows). 

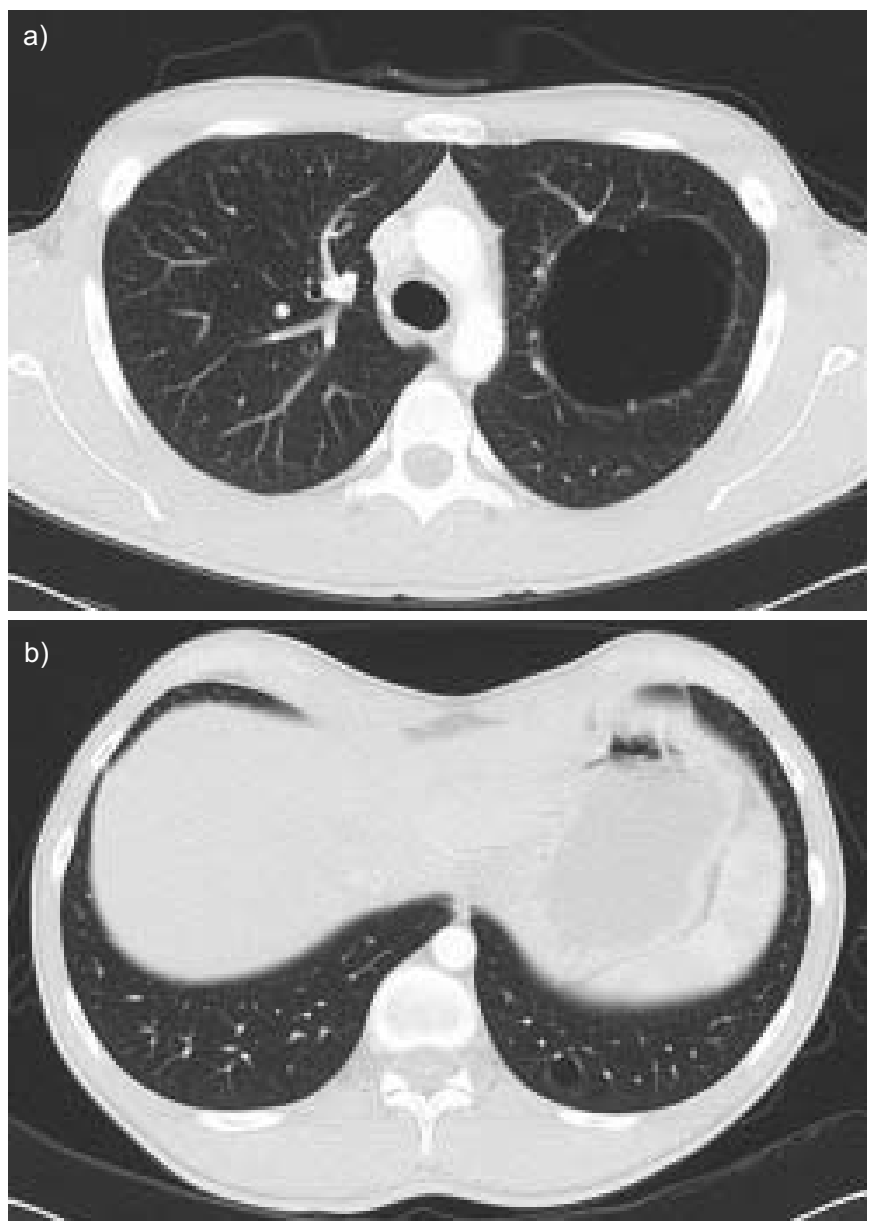

FIGURE 2. Computed tomographic scan showing a) a 9-cm thin-walled cystic airspace in the left upper lobe with peripheral vessels and $b$ ) a further cystic lesion in the posterobasal segment of the left lower lobe.

present case and two of the three previously reported cases, there was no radiological evidence of pneumothorax or pneumomediastinum. In only one previously reported case was pneumothorax observed, which the authors thereof felt was probably iatrogenic following an unsuccessful attempted drain insertion [3].

The term CCAM of the lung encompasses a spectrum of abnormalities ranging from those thought to be related to disordered airway development (types 0,1 and 2) to the far rarer type-4 lesion, which appears to be more of an abnormality in the development of alveolar parenchyma [1]. Although CCAMs usually present before the age of 2 yrs, presentation may be delayed until adulthood [2]. Indeed, CCAMs accounted for $25 \%$ of cystic lung lesions presenting in adults in the present authors surgical series, the remainder being accounted for by simple cysts, sequestrations and bronchial atresia [6]. Type-4 CCAMs are rare overall, accounting for $\leqslant 15 \%$ of all CCAMs [1, 2]. They are peripheral, typically solitary lesions, comprising thin-walled cystic spaces lined predominantly by pneumocytes with the intervening stroma being generally of low cellularity and showing no cytological atypia [1]. However, opinion is divided over the extent to which type-4 CCAMs overlap with purely cystic type-1 pleuropulmonary blastomas $[7,8]$; this is likely to

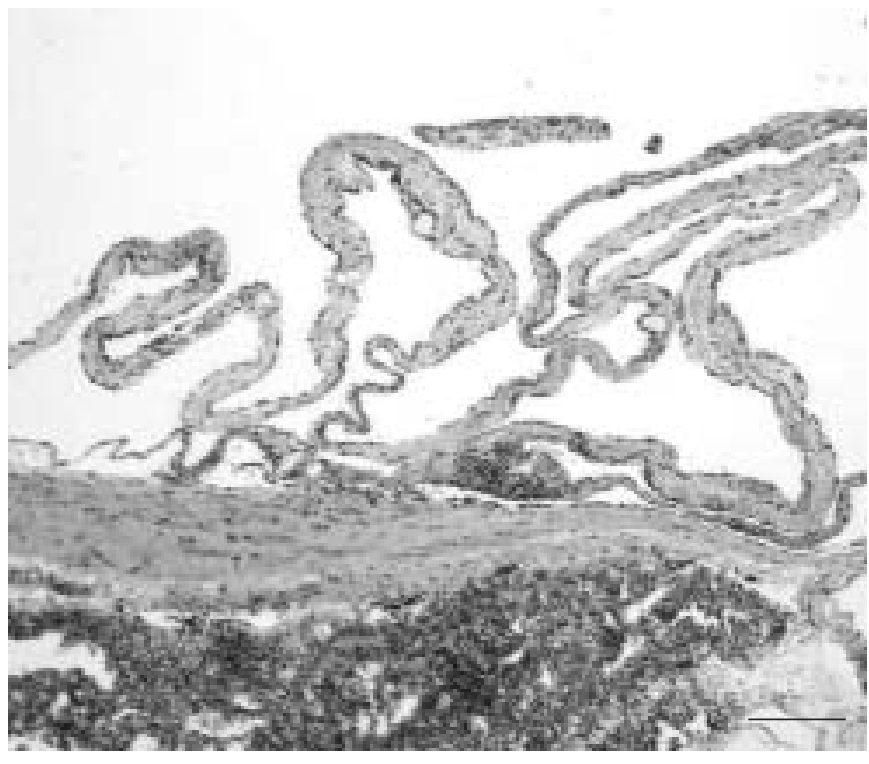

FIGURE 3. A type-4 congenital cystic adenomatoid malformation comprising a multiloculated localised area of cystic change with numerous thin-walled septa Haematoxylin and eosin stain. Scale bar $=1 \mu \mathrm{m}$.

reflect some published cases of sarcomas said to arise in congenital cysts. In the present case, with no significant cellularity or cytological atypia despite widespread sampling, a diagnosis of type-4 CCAM was preferred.

Systemic air embolisation is a recognised complication of intrapulmonary cysts and its occurrence is unpredictable. To the authors' knowledge, the present case is the first report of a CCAM presenting as an in-flight neurological event, which is believed to be secondary to cerebral air embolisation. Although rare, the exact prevalence of asymptomatic intrapulmonary cysts is unclear. The risk of symptomatic air embolisation during air travel in such a patient is unknown. This patient had flown on several previous occasions without incident. The management of air embolism is essentially supportive. The mainstays of treatment are an inspiratory oxygen fraction of 1 to facilitate nitrogen washout, together with hyperbaric oxygen therapy, subject to availability, to reduce the volume of entrained air and increase its absorption rate. A previous report of the use of hyperbaric oxygen therapy instituted $48 \mathrm{~h}$ following an in-flight air embolus resulted in rapid resolution of symptoms [5]. Given that mortality, even with such supportive measures, appears high when embolisation does occur, the present authors suggest that patients with asymptomatic intrapulmonary cysts should be advised against activities leading to rapid changes in ambient pressure or consider elective surgical treatment.

\section{REFERENCES}

1 Stocker JT. Congenital pulmonary airway malformation: a new name for an expanded classification of congenital cystic adenomatoid malformation of the lung. Histopathology 2002; 41: Suppl. 2, 424-458.

2 MacSweeney F, Papagiannopoulos K, Goldstraw P, Sheppard MN, Corrin B, Nicholson AG. An assessment of 
the expanded classification of congenital cystic adenomatoid malformations and their relationship to malignant transformation. Am J Surg Pathol 2003; 27: 1139-1146.

3 Neidhart P, Suter PM. Pulmonary bulla and sudden death in a young aeroplane passenger. Intensive Care Med 1985; 11: 45-47.

4 Zaugg M, Kaplan V, Widmer U, Baumann PC, Russi EW. Fatal air embolism in an airplane passenger with a giant intrapulmonary bronchogenic cyst. Am J Respir Crit Care Med 1998; 157: 1686-1689.

5 Closon M, Vivier E, Breynaert C, et al. Air embolism during an aircraft flight in a passenger with a pulmonary cyst: a favorable outcome with hyperbaric therapy. Anesthesiology 2004; 101: 539-542.

6 Papagiannopoulos K, Hughes S, Nicholson AG, Goldstraw P. Cystic lung lesions in the pediatric and adult population: surgical experience at the Brompton Hospital. Ann Thorac Surg 2002; 73: 1594-1598.

7 Langston C. New concepts in the pathology of congenital lung malformations. Semin Pediatr Surg 2003; 12 17-37.

8 Hill DA, Dehner LP. A cautionary note about congenital cystic adenomatoid malformation (CCAM) type 4. Am J Surg Pathol 2004; 28: 554-555. 